\title{
Determination of nanogram microparticles from explosives after real open-air explosions by confocal Raman microscopy
}

\author{
Félix Zapata, Carmen García-Ruiz*
}

Department of Analytical Chemistry, Physical Chemistry and Chemical Engineering and University Institute of Research in Police Sciences (IUICP), University of Alcalá, Ctra. Madrid-Barcelona km 33.600, 28871 Alcalá de Henares (Madrid), Spain.

Email: carmen.gruiz@uah.es; felix.zapata@uah.es

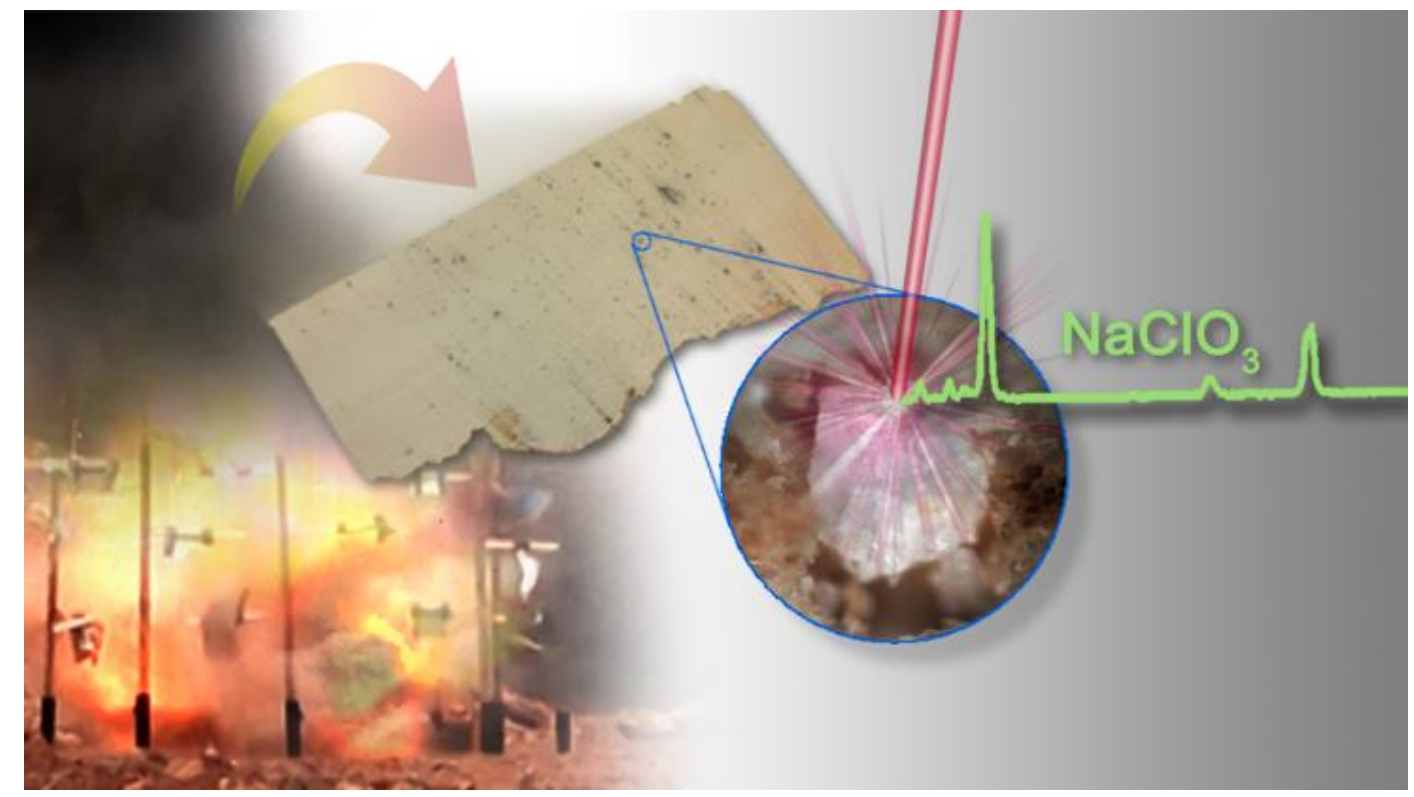

Cite: F. Zapata, C. García-Ruiz, Determination of nanogram microparticles from explosives after real open-air explosions by confocal Raman microscopy, Anal. Chem. 88 (2016) 6726-6733. DOI: 10.1021/acs.analchem.6b00927

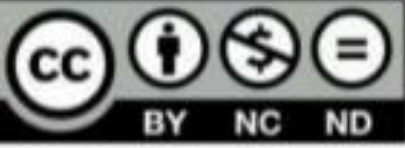




\begin{abstract}
Explosives are increasingly being used for terrorist attacks to cause devastating explosions. The detection of their post-blast residues after an explosion is a high challenge, which has been barely investigated, particularly using spectroscopic techniques. In this research, a novel methodology using confocal Raman microscopy has been developed for the analysis of post-blast residues from ten open-air explosions caused by ten different explosives (TNT, RDX, PETN, TATP, HMTD, dynamite, black powder, ANFO, chloratite, and ammonal) commonly used in improvised explosive devices. The methodology for the determination of post-blast particles from explosives consisted of examining the samples surfaces with both the naked eye, first, and microscopically (10x and 50x), immediately afterward; and finally, analysing the selected residues by confocal Raman spectroscopy in order to identify the post-blast particles from explosives. Interestingly, confocal Raman microscopy has demonstrated to be highly suitable to rapidly, selectively and non-invasively analyse post-blast microscopic particles from explosives up to the nanogram range.
\end{abstract}

Keywords: Black powder, Dynamite, Post-blast residues, Raman microscopy, TATP, Trinitrotoluene. 


\section{Introduction}

The use of explosives for terrorist purposes has become a worldwide persistent threat. Numerous dreadful terrorist attacks have shown the harm and destruction that Improvised Explosive Devices (IEDs) may cause. ${ }^{1}$ The early detection of suspicious-looking IEDs is mandatory to prevent terrorist attacks. Military and police forces and forensic laboratories along the world spare no effort to achieve the detection of explosives before they cause an explosion. Numerous analytical techniques have been deeply investigated for explosives detection and highly significant improvements in terms of selectivity, sensitivity and limit of detection, amongst others, have been achieved. ${ }^{2,3}$ However, the vast majority of studies have focused on the analysis of "pre-exploded" explosives i.e. without having been exploded. The analysis of post-blast residues, which is an overwhelming challenge because of the almost completely consumption and destruction of the original explosive, the vast dispersion of post-blast residues, the trace amount of those explosives residues and the high contamination of the zone, has been quite less researched. Within the few studies focused on post-blast residues analysis, most of them have been accomplished using liquid ${ }^{4-6}$ or gas chromatography ${ }^{7,8}$ coupled with mass spectrometry 9-13 for organic explosives; and ion chromatography or capillary electrophoresis for inorganic explosive mixtures. ${ }^{14-22}$ Nevertheless, these techniques are time and reagent consuming. They require laborious sample preparations and they are destructive. On the contrary, spectroscopic techniques are rapid, non-destructive and do not require any sample treatment. However, they have been barely investigated for postblast residues detection. Interestingly, despite having been little studied, infrared (IR) spectroscopy and, to a lesser extent, Raman spectroscopy have been preliminary examined for post-blast residues detection.

IR spectroscopy has been studied for the detection of post-blast residues of trinitrotoluene (TNT), dynamite, pentaerythritol tetranitrate (PETN) and cyclotrimethylene trinitramine $(\mathrm{RDX})^{23-25}$ as well as black powder and other pyrotechnic compositions. ${ }^{26}$ On the other hand, to the best of our knowledge, Raman spectroscopy, in the imaging mode, has been studied only once for rapidly scanning and detecting post-blast residues from different explosives including TNT, PETN, RDX and black powder along the surface of banknotes

after an automatic teller machine explosion. ${ }^{27}$ However, the high speed of scanning of Raman imaging is usually achieved at the expense of both spatial and spectral resolution, 
being particularly crucial when extremely large surfaces must be analysed. In fact, these few studies have demonstrated that post-blast residues can be easily detected in small explosions of few grams of explosive performed inside a container, ${ }^{24-26}$ but extremely complicated when post-blast residues from real open air explosions are spread out over large areas. ${ }^{23}$ In this work, confocal Raman microscopy has been studied for the determination of post-blast particles from a large variety of explosives usable in IEDs tackling the analysis of the post-blast residues collected from ten real open-air explosions of ten different explosives.

\section{Experimental}

\section{Explosives}

Ten different explosives were considered in this study including: TNT, RDX, PETN, triacetone triperoxide (TATP), hexamethylene triperoxide diamine (HMTD), black powder, chloratite, dynamite, ammonium nitrate fuel oil (ANFO) and ammonal. The ten explosives were obtained from TEDAX, the Spanish Explosive Ordnance Disposal (EOD). In order to clarify, Table 1 correlates each explosive with its composition, according to the information provided either by the manufacturer or by the EOD specialists.

Table 1. Composition of the explosives studied in this work. Information provided by the manufacturer ${ }^{\mathrm{a}}$ or TEDAX (the Spanish EOD) ${ }^{\mathrm{b}}$.

\begin{tabular}{|c|c|}
\hline Explosive & Composition \\
\hline $\mathrm{TNT}^{\mathrm{b}}$ & 2,4,6-Trinitrotoluene $(100 \%)$ \\
\hline $\begin{array}{l}\text { Plastic explosive } \\
\quad(\text { RDX })^{\text {b }}\end{array}$ & $\begin{array}{c}\text { Cyclotrimethylene trinitramine }(91 \%)+\operatorname{Bis}(2 \text {-ethylhexyl) phthalate }(5.3 \%)+ \\
\text { polyisobutylene }(2.1 \%)+\text { motor oil }(1.6 \%)\end{array}$ \\
\hline PETN $^{\mathrm{b}}$ & Pentaerythritol tetranitrate $(100 \%)$ \\
\hline TATP $^{\mathrm{b}}$ & Triacetone triperoxide $(100 \%)$ \\
\hline HMTD $^{b}$ & Hexamethylene triperoxide diamine (100\%) \\
\hline Black powder $^{a}$ & Potassium nitrate $(75 \%)+$ charcoal $(15 \%)+$ sulfur $(10 \%)$ \\
\hline Chloratite $^{\mathrm{b}}$ & Sodium chlorate $(80 \%)+$ sugar $(10 \%)+$ sulfur $(10 \%)$ \\
\hline Dynamite $^{a}$ & $\begin{array}{l}\text { Ammonium nitrate }(66 \%)+\text { ethylene glycol dinitrate }(29 \%)+\text { nitrocellulose }(1 \%) \\
+ \text { dibutyl phthalate }(2.5 \%)+\text { sawdust }(1.2 \%)+\text { calcium carbonate }(0.3 \%)\end{array}$ \\
\hline $\mathrm{ANFO}^{\mathrm{b}}$ & Ammonium nitrate $(90 \%)+$ diesel $(10 \%)$ \\
\hline Ammonal $^{\mathrm{b}}$ & Ammonium nitrate $(85 \%)+$ aluminium $(15 \%)$ \\
\hline
\end{tabular}


The ten improvised explosive devices (IEDs) containing around $300 \mathrm{~g}$ of each explosive were prepared by the EOD specialists. These IEDs were exploded in ten separate explosions (one explosion per explosive). They were exploded in open air simulating real explosions. The weather conditions during each explosion are collected in Table 2. Various pieces of plywood $(20 \times 15 \mathrm{~cm})$ were used as "catchers", i.e. they were place surrounding the explosive at a distance of 1.5-2 metres in order to study the detection of post blast residues on them. Those "catchers" were collected and sealed after each explosion by EOD specialists and they were carried out to the laboratory where they were analysed by Raman microscopy.

Table 2. Weather conditions during the explosions.

\begin{tabular}{|c|c|c|c|c|c|}
\hline Explosion & $\begin{array}{c}\text { Temp } \\
\left({ }^{\circ} \mathbf{C}\right)\end{array}$ & $\begin{array}{c}\text { Humidity } \\
\mathbf{\%}\end{array}$ & $\begin{array}{c}\text { Atmospheric } \\
\text { pressure }(\mathbf{m b})\end{array}$ & $\begin{array}{c}\text { Wind } \\
\text { direction }\end{array}$ & $\begin{array}{c}\text { Wind speed } \\
(\mathbf{k m} / \mathbf{h})\end{array}$ \\
\hline TNT & 1.1 & 54 & 1017.1 & $246 \mathrm{WSW}$ & 4.8 \\
\hline RDX & 2.4 & 72 & 1007.0 & $280 \mathrm{~W}$ & 24.1 \\
\hline PETN & 2.3 & 53 & 1017.8 & $198 \mathrm{SSW}$ & 1.6 \\
\hline TATP & 5.1 & 89 & 1007.8 & $262 \mathrm{~W}$ & 22.5 \\
\hline HMTD & 5.9 & 87 & 1007.7 & $271 \mathrm{~W}$ & 20.9 \\
\hline Black powder & 7.6 & 80 & 1007.0 & $277 \mathrm{~W}$ & 17.7 \\
\hline Chloratite & NA & NA & NA & NA & NA \\
\hline Dynamite & 1.8 & 67 & 1006.4 & $265 \mathrm{~W}$ & 12.9 \\
\hline ANFO & 0.7 & 72 & 1006.1 & $250 \mathrm{WSW}$ & 9.7 \\
\hline Ammonal & NA & NA & NA & NA & NA \\
\hline
\end{tabular}

NA: Not available. The weather conditions during explosions of chloratite and ammonal were not registered because the weather station was not available that day.

\section{Instrumentation}

Raman microscopic analysis were performed with a Thermo Scientific DXR Raman microscope (Waltham, MA, USA) using the Thermo Scientific Omnic for dispersive Raman 8 software (Waltham, MA, USA). Samples were microscopically observed in minute detail using 10x, 20x and 50x microscope objectives. After finding a potential suspicious post-blast residue, that spot was analysed by Raman spectroscopy. Raman measurements were performed using a $780 \mathrm{~nm}$ excitation wavelength of $10 \mathrm{~mW}$ power and 400 lines $\mathrm{mm}^{-1}$ grating. The Raman spectra were measured from 2500 to $200 \mathrm{~cm}^{-1}$ (with a spectral data spacing of $0.964 \mathrm{~cm}^{-1}$ ). The spectra acquisition for all samples involved the accumulation of 5 scans of $6 \mathrm{~s}$ per scan. These parameters were fixed by demonstrating they were suitable to obtain Raman spectra of high signal-to-noise ratio 
from the first post-blast residue which was analysed (the ammonium nitrate post-blast residues from ANFO).

\section{Data treatment}

Raman spectra from the post blast-residues were visually and statistically (Pearson correlation) compared with the spectral library which had been previously created from the standards of the pre-exploded explosives. This comparison was directly performed in the Thermo Scientific Omnic for dispersive Raman 8 software. In order to demonstrate the accuracy of the characteristic Raman spectra from post-blast residues when the particles from residues are properly focused and analysed, these spectra were used for the comparison as they were obtained. They were not processed by any pre-processing method, neither baseline correction, normalization nor smoothing. Interestingly, the Raman spectra from those correctly focused post-blast particles mostly provided a correlation coefficient above 0.90 .

\section{Results and discussion}

\section{Raman spectral library of pre-exploded explosives}

First of all, standards from the ten explosives prior their explosion were analysed by Raman microscopy in order to create a useful compounds library containing the Raman spectra of those explosives which were necessary to subsequently compare and identify the compounds contained in the post-blast residues. The Raman spectra of the ten explosives studied are displayed in Figure 1. As expected, the homogeneous organic explosives (TNT, RDX, PETN, TATP and HMTD) provided a unique representative spectrum due to their characteristic molecular vibrations. On the contrary, with regard to the heterogeneous explosive mixtures (black powder, dynamite, chloratite, ANFO and ammonal), the Raman spectrum strongly depended on the component predominantly present within the focused spot. Thus, their Raman spectrum mostly corresponded to the main component since it was predominant in most of the spots collected along the standard. 


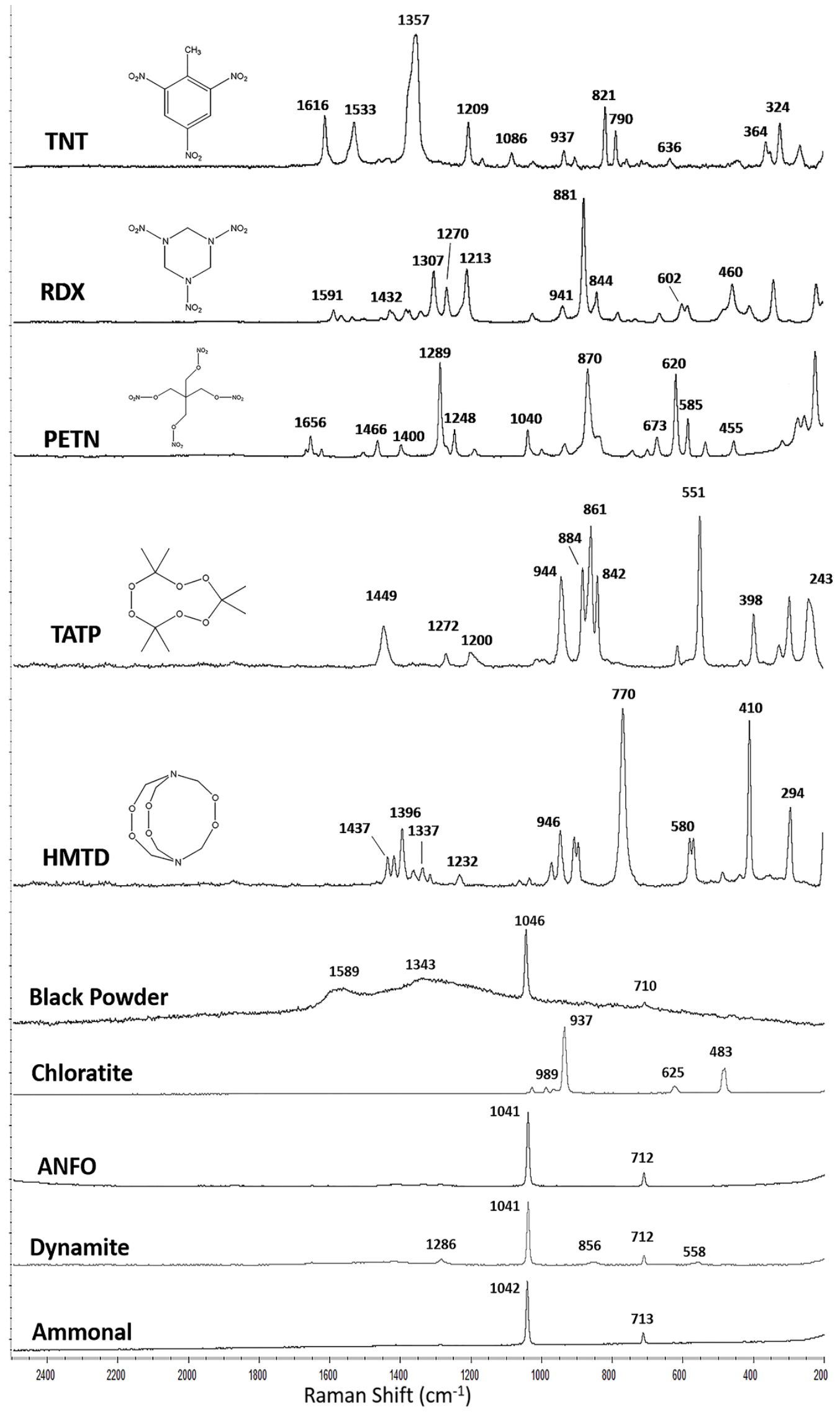

Figure 1: Raman spectra of TNT, RDX, PETN, TATP, HMTD, black powder, ANFO, dynamite, ammonal and chloratite. Raman conditions: laser at $780 \mathrm{~nm}, 14.0 \mathrm{~mW}, 10 \mathrm{x}$ magnification objective, confocal pinhole of $50 \mu \mathrm{m}$, spectra collected by 6 acquisitions of $5 \mathrm{~s}$ per acquisition. 
As shown in Figure 1, Raman spectra from TNT, RDX, PETN, TATP and HMTD displayed numerous bands, contrary to black powder, chloratite, dynamite, ANFO and ammonal which provided few bands. This difference is indeed due to the fact that TNT, RDX, PETN, TATP and HMTD are organic compounds (with multiple covalent bonds) whereas black powder, chloratite, dynamite, ANFO and ammonal are mostly inorganic mixtures of ionic compounds. In fact, the Raman spectrum from black powder, chloratite, dynamite, ANFO and ammonal is mainly dominated by the main and major component of these explosive mixtures, i.e. the oxidizing inorganic salts of potassium or ammonium nitrates or sodium chlorate. However, there are some mixtures in which weak bands due to a second component are also visible such as black powder or dynamite. In order to provide a comprehensive understanding about these Raman vibrations, Table 3 summarizes the frequencies assignments to the molecular vibrations for the main observed bands according to the literature..$^{26,28-40}$

Table 3. Summary of the main Raman bands from the spectra displayed in Figure 1 and their assignment with the fundamental vibrations. (asym: antisymmetric, bend: bending, def: deformation, ip: in-plane, oop: out-of-plane, rock: rocking, scis: scissoring, str: stretching, sym: symmetric, twist: twisting, wag: wagging).

\begin{tabular}{|c|c|c|c|c|}
\hline Explosive & Formula & $\begin{array}{c}\text { Raman } \\
\text { shift } \\
\left(\mathrm{cm}^{-1}\right)\end{array}$ & Frequencies assignments to molecular vibrations & References \\
\hline TNT & $\mathrm{C}_{7} \mathrm{H}_{5} \mathrm{~N}_{3} \mathrm{O}_{6}$ & $\begin{array}{c}1616 \\
1533 \\
1357 \\
1209 \\
1086 \\
937 \\
821 \\
790 \\
636 \\
364 \\
324\end{array}$ & $\begin{array}{c}\mathrm{C}-\mathrm{C} \text { aromatic str or } 2,6-\mathrm{NO}_{2} \text { asym str } \\
\mathrm{NO}_{2} \text { asym str } \\
\mathrm{NO}_{2} \text { sym str } \\
\text { ring breathing or } \mathrm{C}_{6} \mathrm{H}_{2}-\mathrm{C} \text { vibration } \\
\mathrm{C}-\mathrm{H} \text { ip bend } \\
\mathrm{C}-\mathrm{N} \text { str or } \mathrm{C}-\mathrm{H} \text { oop bend } \\
\mathrm{NO}_{2} \text { scis } \\
\mathrm{C}-\mathrm{CH}_{3} \text { str, } \mathrm{NO}_{2} \text { scis or } \mathrm{C}-\mathrm{H} \text { oop bend } \\
\mathrm{C}-\mathrm{C} \text { ring bend } \\
\mathrm{CH}_{3} \text { def } \\
2,4,6 \mathrm{C}-\mathrm{N} \text { ip torsion }\end{array}$ & $28-32$ \\
\hline RDX & $\mathrm{C}_{3} \mathrm{H}_{6} \mathrm{~N}_{6} \mathrm{O}_{6}$ & $\begin{array}{l}1591 \\
1432 \\
1307 \\
1270 \\
1213 \\
941 \\
881 \\
844 \\
602 \\
460\end{array}$ & $\begin{array}{c}\mathrm{NO}_{2} \text { asym str } \\
\mathrm{H}-\mathrm{C}-\mathrm{N} \text { bend } \\
\mathrm{CH}_{2} \text { wag, } \mathrm{CH}_{2} \text { twist or N-N str } \\
\mathrm{CH}_{2} \text { scis or } \mathrm{N}-\mathrm{N} \text { str } \\
\mathrm{CH}_{2} \text { rock } \\
\mathrm{C}-\mathrm{N} \text { str, } \mathrm{CH}_{2} \text { rock or N-N str } \\
\mathrm{C}-\mathrm{N} \text { str or } \mathrm{N}-\mathrm{N} \text { str } \\
\mathrm{N}-\mathrm{N} \text { str or } \mathrm{NO}_{2} \text { scis } \\
\text { O-C-O str } \\
\text { ip ring bend }\end{array}$ & $31-33$ \\
\hline
\end{tabular}




\begin{tabular}{|c|c|c|c|c|}
\hline PETN & $\mathrm{C}_{5} \mathrm{H}_{8} \mathrm{~N}_{4} \mathrm{O}_{12}$ & $\begin{array}{l}1656 \\
1466 \\
1400 \\
1289 \\
1248 \\
1040 \\
870 \\
673 \\
620 \\
585 \\
455\end{array}$ & $\begin{array}{c}\mathrm{NO}_{2} \text { asym str } \\
\mathrm{NO}_{2} \text { asym str or } \mathrm{CH}_{2} \text { scis } \\
\mathrm{CH}_{2} \text { wag or } \mathrm{C}-\mathrm{C} \text { str } \\
\mathrm{NO}_{2} \text { sym str or } \mathrm{CH}_{2} \text { wag } \\
\text { C-H bend } \\
\mathrm{CH}_{2} \text { torsion or } \mathrm{C}-\mathrm{C} \text { bend } \\
\mathrm{O}(\text { ester)-N str or } \mathrm{C}-\mathrm{C} \text { str } \\
\mathrm{O} \text { (ester)- } \mathrm{N} \text { str, } \mathrm{C}-\mathrm{C} \text { str or } \mathrm{NO}_{2} \text { scis } \\
\mathrm{C}-\mathrm{C}-\mathrm{C} \text { def or } \mathrm{ONO} \text { rock } \\
\text { ONO} \text { rock or } \mathrm{C}-\mathrm{C} \text { bend } \\
\text { C-C-C def, } \mathrm{O} \text { (ester)- } \mathrm{N} \text { str or } \mathrm{NO}_{2} \text { rock }\end{array}$ & $32-34$ \\
\hline TATP & $\mathrm{C}_{9} \mathrm{H}_{18} \mathrm{O}_{6}$ & $\begin{array}{l}1449 \\
1272 \\
1200 \\
944 \\
884 \\
861 \\
842 \\
551 \\
398 \\
243\end{array}$ & $\begin{array}{c}\text { C-C str or } \mathrm{CH}_{3} \text { asym bend } \\
\text { Sym ring breathing } \\
\text { O-C-O and } \mathrm{Me}-\mathrm{C}-\mathrm{Me} \text { asym str or Me-C-O sym str } \\
\text { asym ring breathing } \\
\text { O-C-O and Me-C-Me asym str or Me-C-O str } \\
\text { O-O str, O-C-O and Me-C-Me sym str } \\
\text { asym ring breathing } \\
\text { O-C-O scis } \\
\text { ring breathing } \\
\text { C-O-O-C shear }\end{array}$ & $32,35,36$ \\
\hline HMTD & $\mathrm{C}_{6} \mathrm{H}_{12} \mathrm{~N}_{2} \mathrm{O}_{6}$ & $\begin{array}{c}1437 \\
1396 \\
1337 \\
1232 \\
946 \\
770 \\
580 \\
410 \\
294\end{array}$ & $\begin{array}{c}\mathrm{CH}_{2} \text { scis } \\
\mathrm{CH}_{2} \text { wag } \\
\mathrm{CH}_{2} \text { twist } \\
\mathrm{C}-\mathrm{N} \text { str } \\
\mathrm{C}-\mathrm{O} \text { str } \\
\mathrm{O}-\mathrm{O} \text { str } \\
\mathrm{Ring} \mathrm{str} \\
\mathrm{NCO} \text { def } \\
\mathrm{CN} \text { bend or O-O torsion }\end{array}$ & $32,36,37$ \\
\hline Black powder & $\mathrm{KNO}_{3}$ & $\begin{array}{c}1589 \\
1343 \\
1047 \\
711\end{array}$ & $\begin{array}{l}\text { Fluorescence from charcoal } \\
\text { Fluorescence from charcoal } \\
\mathrm{NO}_{3} \text { sym str }\left(\mathrm{KNO}_{3}\right) \\
\mathrm{NO}_{3} \text { ip def }\left(\mathrm{KNO}_{3}\right)\end{array}$ & 26,38 \\
\hline Chloratite & $\mathrm{KClO}_{3}$ & $\begin{array}{l}989 \\
937 \\
625 \\
483\end{array}$ & $\begin{array}{l}\mathrm{ClO}_{3} \text { asym str }\left(\mathrm{KClO}_{3}\right) \\
\mathrm{ClO}_{3} \text { sym str }\left(\mathrm{KClO}_{3}\right) \\
\mathrm{ClO}_{3} \text { sym def }\left(\mathrm{KClO}_{3}\right) \\
\mathrm{ClO}_{3} \text { asym def }\left(\mathrm{KClO}_{3}\right)\end{array}$ & 26,38 \\
\hline Dynamite & $\mathrm{NH}_{4} \mathrm{NO}_{3}$ & $\begin{array}{c}1286 \\
1041 \\
856 \\
713 \\
558\end{array}$ & $\begin{array}{c}\mathrm{NO}_{2} \text { sym str }(\mathrm{EGDN}) \\
\mathrm{NO}_{3} \text { sym str }\left(\mathrm{NH}_{4} \mathrm{NO}_{3}\right) \\
\mathrm{O}(\text { ester })-\mathrm{N} \text { str or } \mathrm{C}-\mathrm{C} \text { str }(\mathrm{EGDN}) \\
\mathrm{NO}_{3} \text { ip def }\left(\mathrm{NH}_{4} \mathrm{NO}_{3}\right) \\
\mathrm{ONO}_{2} \text { rock or } \mathrm{C}-\mathrm{C} \text { bend }(\mathrm{EGDN})\end{array}$ & $38-40$ \\
\hline ANFO & $\mathrm{NH}_{4} \mathrm{NO}_{3}$ & $\begin{array}{c}1041 \\
713\end{array}$ & $\begin{array}{c}\mathrm{NO}_{3} \text { sym } \operatorname{str}\left(\mathrm{NH}_{4} \mathrm{NO}_{3}\right) \\
\mathrm{NO}_{3} \text { ip def }\left(\mathrm{NH}_{4} \mathrm{NO}_{3}\right)\end{array}$ & 38,40 \\
\hline Ammonal & $\mathrm{NH}_{4} \mathrm{NO}_{3}$ & $\begin{array}{c}1041 \\
713\end{array}$ & $\begin{array}{c}\mathrm{NO}_{3} \text { sym } \operatorname{str}\left(\mathrm{NH}_{4} \mathrm{NO}_{3}\right) \\
\mathrm{NO}_{3} \text { ip def }\left(\mathrm{NH}_{4} \mathrm{NO}_{3}\right)\end{array}$ & 38,40 \\
\hline
\end{tabular}


Although TNT, RDX and PETN are all nitro-compounds, they belong to different chemical families due to their differences in the bond type between their chemical nitrogroups and the rest of the molecule. Consequently, they provided different characteristic Raman bands and, therefore, different Raman spectra. For instance, the Raman spectrum of TNT, which is a nitroarene (bond $\mathrm{C}-\mathrm{NO}_{2}$ ), is dominated by the $\mathrm{NO}_{2}$ symmetric stretching vibration whose band is located at $1357 \mathrm{~cm}^{-1}$. The Raman spectrum of RDX, which is a nitramine (bond $\mathrm{N}-\mathrm{NO}_{2}$ ), displayed the most prominent band at $881 \mathrm{~cm}^{-1}$ corresponding to $\mathrm{C}-\mathrm{N}$ or N-N stretching vibrations. And PETN, which is a nitro ester (bond $\mathrm{O}-\mathrm{NO}_{2}$ ), provided a Raman spectrum whose most intense bands were those located at 1289 and $870 \mathrm{~cm}^{-1}$ corresponding to $\mathrm{NO}_{2}$ symmetric stretching or $\mathrm{CH}_{2}$ wagging and $\mathrm{O}(\mathrm{ester})-\mathrm{N}$ stretching or C-C stretching, respectively.

The peroxide explosives TATP and HMTD are both characterized by the O-O bond. Nevertheless their notable differences in their chemical structure are clearly reflected in their different Raman spectra. The spectrum of TATP is dominated by two bands located at 861 and $551 \mathrm{~cm}^{-1}$, which are due to O-O stretching, O-C-O or Me-C-Me symmetric stretching and O-C-O scissoring respectively, whereas HMTD displayed its characteristic prominent bands at 770 and $410 \mathrm{~cm}^{-1}$ corresponding to $\mathrm{O}-\mathrm{O}$ stretching and $\mathrm{N}-\mathrm{C}-\mathrm{O}$ deformation.

The energetic explosive mixtures are characterized by the presence of an oxidizing inorganic salt. The five explosive mixtures can be grouped in three classes according to the different oxidizing salt. Black powder contains potassium nitrate, chloratite is composed by sodium chlorate whereas dynamite, ANFO and ammonal contain ammonium nitrate (see Table 1). Thus, the Raman spectrum of black powder clearly displayed the characteristic bands of potassium nitrate placed at 1047 and $711 \mathrm{~cm}^{-1}$. Two wide and weak bands located at 1589 and $1343 \mathrm{~cm}^{-1}$, which both were due to charcoal fluorescence, also appeared in the spectrum. However, no bands from sulfur were visible in the spectrum, probably due to the small amount of sulfur in the mixture. Chloratite displayed a Raman spectrum dominated by the characteristic bands of sodium chlorate, which were located at 989, 937, 625 and $483 \mathrm{~cm}^{-1}$. In addition, the Raman spectra of dynamite, ANFO and ammonal clearly showed the characteristic bands of ammonium nitrate located at 1041 and $713 \mathrm{~cm}^{-1}$. In fact, the ammonium nitrate is the unique compound which can be assigned from the spectra except for dynamite whose spectrum 
revealed another three weak bands placed at 1286, 856 and $558 \mathrm{~cm}^{-1}$, which can be attributed to EGDN. ${ }^{39}$

The spectral analysis of the explosive mixtures has also shown that sodium chlorate can be clearly distinguished from the potassium and ammonium nitrates. But it should be noted the slight but remarkable difference between potassium and ammonium nitrates. The high specificity of Raman spectroscopy allowed to distinguish a slight difference of $6 \mathrm{~cm}^{-1}$ in Raman shift between the $\mathrm{NO}_{3}$ symmetric stretching from potassium and ammonium nitrate, as previously reported by Zapata et al. ${ }^{41}$ In fact, this difference, which was properly measured using an instrumental precision of $\pm 2 \mathrm{~cm}^{-1}$, can be probably caused by the cation influence on the anion vibration. This difference was highly analytically relevant because it allowed us to distinguish and identify both nitrates.

\section{Analytical methodology}

The real challenge of this study involved the identification of post-blast particles from explosives taking part of IEDs after their open-air explosion by confocal Raman microscopy.

First, it is important to note that most prevalent spots along the surface of post-blast samples were the own material, burnt material and particles of ground. Thus, as shown in Figure 2, most of the surface of samples was the own material (plywood in this case), whose spots provided the characteristic Raman spectrum of the material, which had quite a lot of noise and displayed a characteristic band at $1598 \mathrm{~cm}^{-1}$. Some parts were burnt material, probably caused by the heat from the explosion. These burnt spots provided Raman spectra with high fluorescence. Some particles which seemed particles of ground appeared scattered along the surface of collected samples. They were confirmed as particles of calcite (calcium carbonate) from the ground, since they provided the characteristic band located at $1086 \mathrm{~cm}^{-1}$, which had been previously registered for the sample of ground taken as reference and corroborated by analysing calcium carbonate standard. Undoubtedly, the shock wave caused by the explosion made that many particles of ground flew off in all directions (coming into contact with the samples). 


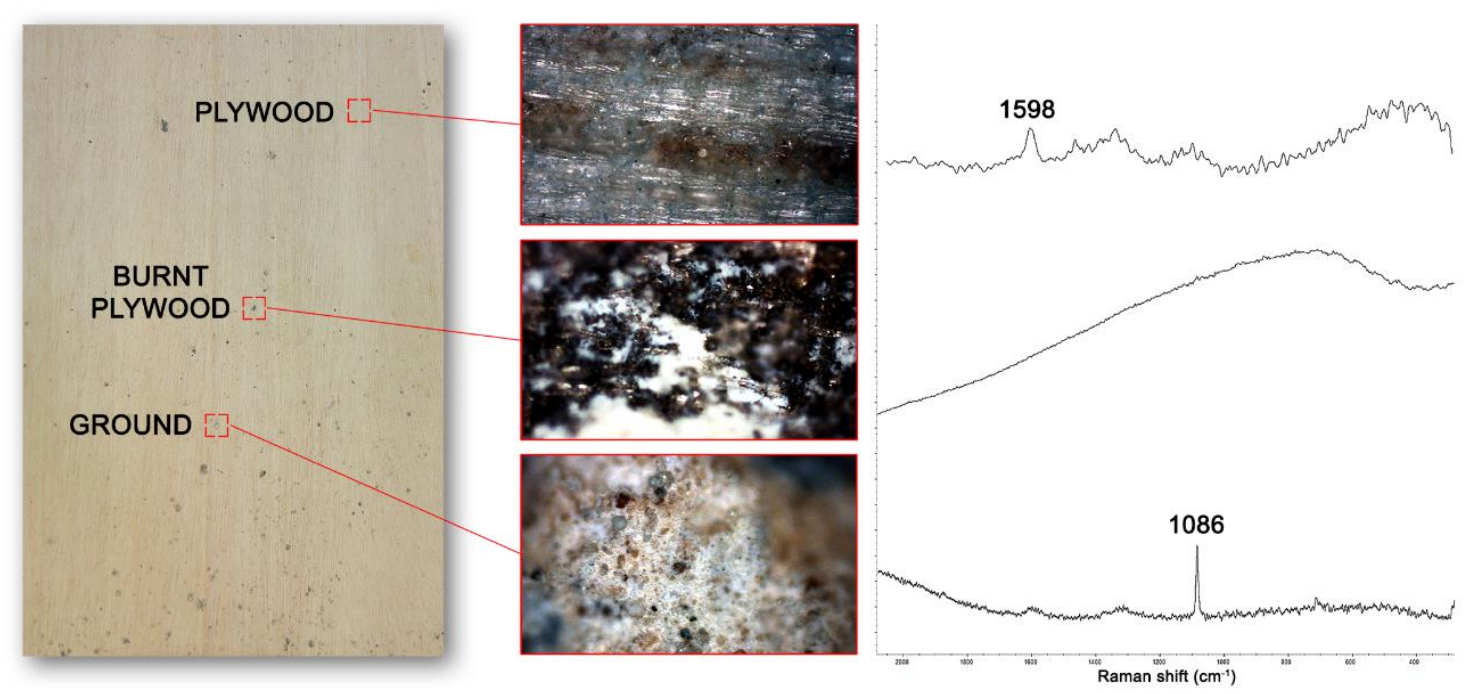

Figure 2: Most prevalent spots found on the post-blast samples surface: own material (above), burnt material (middle), and particles of ground (below). Raman conditions as in Figure 1.

In addition to these prevalent spots, traces of post-blast explosives corresponding with few white microscopic particles spread out along the surface of samples were detected for some of the exploded explosives. Despite being scarce and microscopic, these particles were highly relevant and informative because they were post-blast particles from the explosive which had remained non-reacted during the explosion since they provided the characteristic Raman spectrum of the main components of the original explosive (see Figure 3). As a consequence of the difficulties to determine these post-blast explosive particles, an analytical methodology including three consecutive steps was developed.

A. Examination of the sample with the naked eye (supported by a magnifying glass when necessary).

The examination of samples with the naked eye was focused on scrutinizing macroscopically the surface of samples in search of those regions where the material showed clear evidence of having come into contact with the explosion. In essence, this examination was focused on anything which was foreign to the material, which could be burnt material, ground particles or post-blast particles from the explosive. It is highly recommendable to use a magnifying glass to improve the vision range and discriminate between regions with post-blast evidence, even for rejecting, right from the beginning, those regions that do not show any post-blast evidence. 


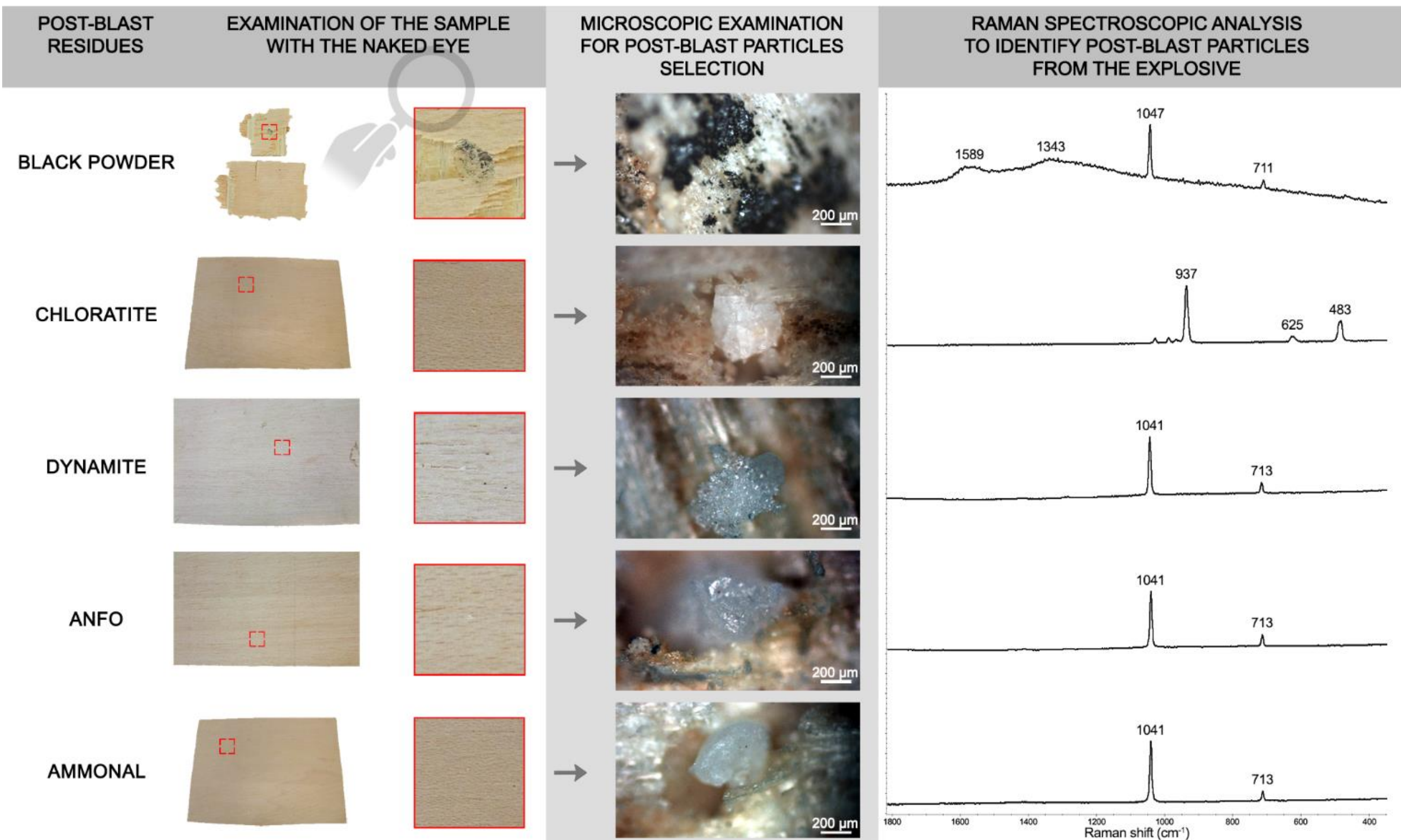

Figure 3: Methodological steps and Raman spectra of post-blast particles from black powder, chloratite, dynamite, ANFO and ammonal. Raman conditions as in Figure 1. 


\section{B. Microscopic examination of the sample for post-blast particles selection.}

After finding, with the naked eye, one of those alleged regions with post-blast evidence, that region was subsequently examined under the Raman microscope at 10x and 50x magnifications in order to microscopically verify or dismiss the presence of post-blast particles from the explosive. After a tentative microscopic identification of these particles, they were always analysed by Raman to confirm their identification.

\section{Raman spectroscopic analysis to identify post-blast particles from the explosive.}

After finding the alleged post-blast-looking particle and selecting and focusing a spot on it, the Raman analysis of that particle was performed providing its characteristic Raman spectrum. This spectrum was compared with the previous database of pre-exploded explosives.

As example, Figure 3 displays the methodology steps and the results obtained for those explosive mixtures based on oxidizing salts.

As shown in Figure 3, the Raman spectra provided by these post-blast particles were surprisingly similar to the spectra previously collected from pre-exploded explosives. Thus, the identification of these particles by checking the spectral database of preexploded explosives was extremely fast and straightforward. In general, a visual comparison of the spectra by focusing on the value of the most prominent bands was enough to identify each particle. Nevertheless, a statistical comparison using Pearson correlation, whose value was usually above 0.95 over 1 , was directly performed (i.e. without spectra pre-processing) using the same Raman software to ensure the identification. These positive results, ultimately provided by the excellent signal-to-noise ratio of the spectra, were due to the exceptional capability of confocal Raman microscopy to focusing just on the post-blast particle of interest in such a way that the Raman spectrum is uniquely determined by the focused particle and not affected by the surrounding material. In fact, this microscopically-facilitated differentiation of particles in the sample, in addition to the high specificity provided by Raman spectroscopy due to the specific molecular vibrations, have turned Raman microscopy into a highly selective technique for discriminating post-blast particles from explosives. 
As also displayed in Figure 3, the size of post-blast particles was studied. The size of the post-blast particles detected and analysed by Raman microscopy ranged from 10 to 500 $\mu \mathrm{m}$ (diameter). Particularly, the particles shown in figure 3 had a diameter around 300 $\mu \mathrm{m}$. Interestingly, taking into account the particles size, the LOD of the developed methodology was estimated through the calculation of the mass of the smallest particles, which was performed as follows. Assuming a cubic or spherical particle with a diameter of $10 \mu \mathrm{m}$ (the smallest particles detected), its volume is $1000 \mu \mathrm{m}^{3}$ (if cubic) or $524 \mu \mathrm{m}^{3}$ (if spherical). As further discussed in section 3.3, these particles corresponded to the oxidizing salt from the explosive. Thus, in the knowledge that potassium nitrate, sodium chlorate and ammonium nitrate have a density of $2.11 \mathrm{~g} / \mathrm{cm}^{3}, 2.50 \mathrm{~g} / \mathrm{cm}^{3}$ and $1.725 \mathrm{~g} / \mathrm{cm}^{3}$, respectively, the mass of the smallest particles determined by Raman microscopy was 2.1 $\mathrm{ng}, 2.5 \mathrm{ng}$ and $1.7 \mathrm{ng}$, respectively, for potassium nitrate, sodium chlorate and ammonium nitrate cubic particles (1.1 ng, $1.3 \mathrm{ng}$ and $0.9 \mathrm{ng}$ if we assume spherical particles). Consequently, trace amounts in the ng range can be detected and identified by Raman microscopy for post-blast residues from explosives.

With regards to the time, it is noteworthy that the whole process only took few minutes per sample, i.e. per piece of plywood of 20x15 cm dimensions. In fact, several iterations of the three-stepped process were accomplished per sample. Around 1 minute was spent for the visual examination of the whole surface in order to select an interesting post-blast region. A post-blast particle was then selected using the microscope and it was analysed by Raman spectroscopy. The Raman analysis only took $30 \mathrm{~s}$. Afterwards, the process started again in search of another particle. In fact, an expert eye (which was achieved in a very short period of time after examining 1 or 2 samples with post-blast particles) easily found those particles at first. 


\section{Post-blast residues analysis}

The developed methodology was followed to analyse the post-blast samples from the ten openair explosions studied in this work. Table 4 collects the post-blast particles detected.

Table 4. Post-blast particles identified after the open-air explosions by confocal Raman microscopy. Those explosives in which post-blast particles from the explosive were identified are remarked in bold letters.

\begin{tabular}{|cc|}
\hline Explosive & Post-blast particles identified after the explosion \\
\hline TNT & None \\
RDX & None \\
PETN & None \\
TATP & None \\
\hline HMTD & None \\
\hline Black powder & Potassium nitrate and charcoal \\
Chloratite & Sodium chlorate \\
\hline Dynamite & Ammonium nitrate \\
ANFO & Ammonium nitrate \\
\hline Ammonal & Ammonium nitrate \\
\hline
\end{tabular}

As shown in Table 4, it is important to emphasize that those explosives whose post-blast particles were detected by confocal Raman microscopy were black powder, chloratite, ANFO, dynamite and ammonal, that is, they are energetic explosive mixtures based on inorganic oxidizing salts. On the contrary, post-blast residues from peroxide explosives and military explosives could not be detected by confocal Raman microscopy. No Raman spectra of TNT, RDX, PETN, TATP or HMTD were registered for any of the post-blast evidence observed in their samples.

The reason for this different behaviour is probably due to the fact that energetic mixtures require the straight contact between their components to produce the combustion reaction between the oxidizing salt and the combustible compound to cause the explosion. Any part of the mixture which is badly mixed (i.e. because of a poor contact between oxidizing and combustible components) will not take part in the reaction and the subsequent shock wave caused by the explosion will through those non-reacted particles of the mixture all around. Moreover, the higher proportion of oxidizing salt in the mixture (see table 1) contributes to that, being reasonable that post-blast non-reacted particles from the oxidizing salt were more frequently detected than the other minor components. For instance, considering the explosion of the explosive device made of black powder, it is understandable that some particles of its major components (potassium nitrate and charcoal) flew off in all directions and some of those remaining particles ended up on the 
samples as shown schematically in Figure 4. In addition, it may be thought that a considerable amount of these particles came from the explosion since the few pieces of plywood (catchers), which were surrounding the explosion, caught several post-blast particles each. A large number of post-blast particles certainly flew off far away and were lost.

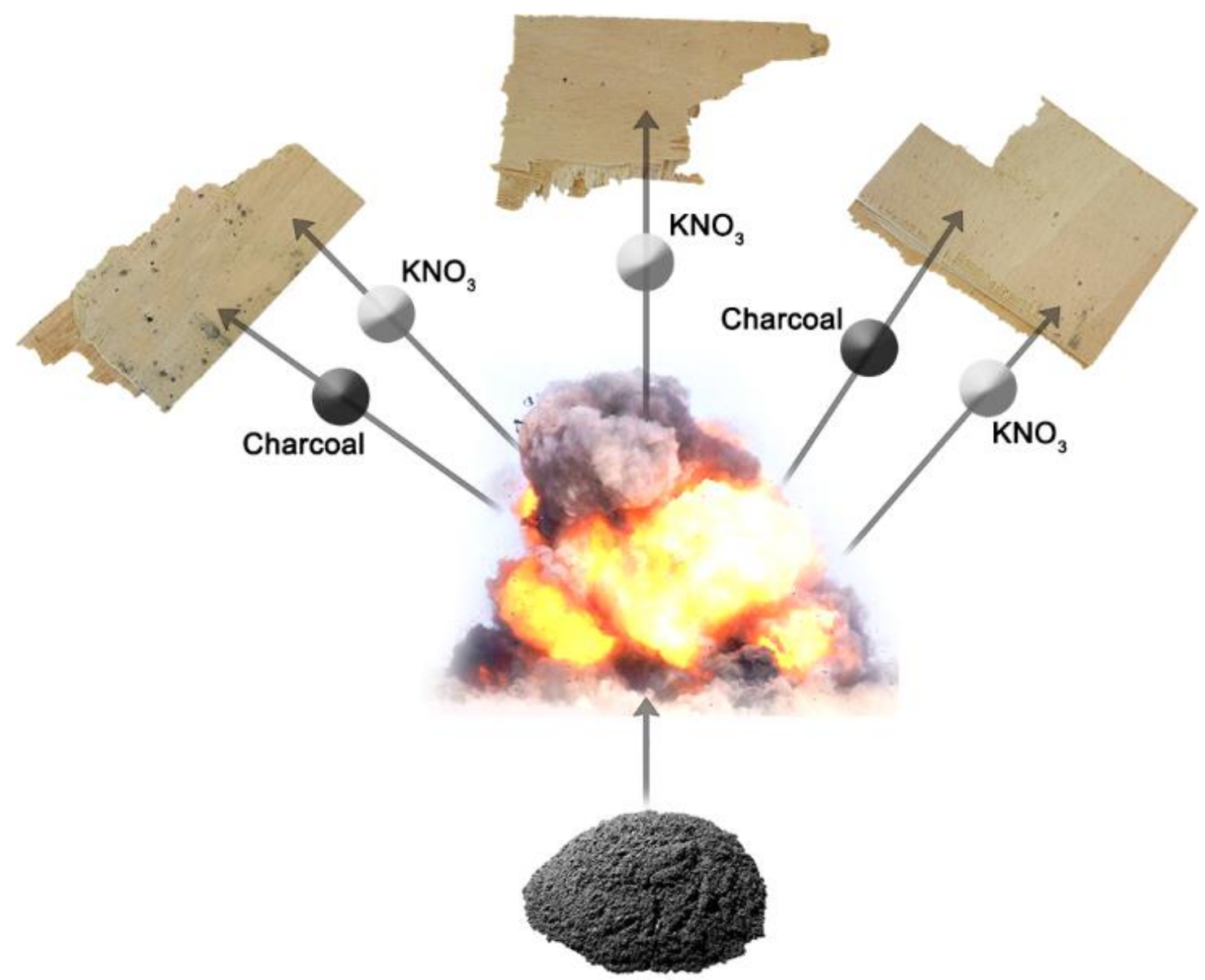

Figure 4: Scheme showing a hypothetical projection of black powder particles after its explosion.

On the other hand, TNT, RDX and PETN military explosives and TATP and HMTD peroxide explosives are pure explosives based on organic compounds (no mixtures). The same molecule reacts as combustible and as oxidizer simultaneously, being a more efficient explosion. Therefore, no non-reacted particles from these explosives remained after the explosion; at least, no particles which were big enough to be analysed by Raman microscopy. 


\section{Conclusions and future trends}

This study has evidenced the capability of confocal Raman microscopy for analysing post-blast particles from explosives after their open-air explosions. To this aim, a spectral database containing the Raman spectra of the explosives taking part of the pre-exploded devices was created. In addition, the Raman spectra of explosives were further characterized by providing, according to the literature, the respective vibrations of the main Raman bands.

Confocal Raman microscopy, which combines both microscopic visualization and Raman spectroscopy has enabled a non-destructive, selective, fast and solvents-free methodology for the detection and identification of microscopic post-blast particles from explosives. Interestingly, the high selectivity and the outstanding estimated LOD in terms of mass of detected particles, through considering the estimated volume of the particle and its density, enabled the detection and identification of post-blast particles up to the ng range. The complementary and consecutive use of microscopy coupled to Raman spectroscopy has demonstrated to be highly suitable for the qualitative determination of post-blast particles from explosives after open-air explosions.

The results achieved from the post-blast analysis revealed that explosive mixtures based on oxidizing salts, after being exploded, were always successfully determined by confocal Raman microscopy through the identification of post-blast non-reacted particles from the oxidizing salt. However, the detection of post-blast non-reacted particles from the organic explosives based on pure compounds (no mixtures) was not possible by this methodology.

Interestingly, this study has also evidenced the great feature of confocal Raman spectroscopy for differentiating between nitrates (potassium and ammonium nitrate), which is a great advance over conventional and routinely used chromatographic and/or electrophoretic techniques that require a sample treatment to dissolve the salt, and dissociate it into its ions.

The choice of the materials in which detecting the post-blast particles by confocal Raman microscopy seems to be a relevant aspect. Although the plywood has demonstrated to be an appropriate surface in which post-blast particles are both easily retained and detected, further studies examining a wider variety of common materials as catchers are being 
performed in order to establish the most appropriate materials that should be collected during evidence recovery in real open-air IEDs explosions.

Further studies by using a portable Raman microscope would be also useful in order to test whether the detection of post-blast particles from explosive mixtures can be performed on-field, an important aspect in military operations. In fact, current portable Raman spectrometers do not usually combine microscopy and, therefore, they are only suitable for the detection of non-exploded explosives in bulk amounts.

\section{Acknowledgements}

The authors thank European Commission for the Project HOME/2011/ISEC/AG/4000002480 funded with the financial support of the Prevention of and Fight against Crime Programme from the European Commission - DirectorateGeneral Home Affairs. This publication reflects the views only of the authors, and the European Commission cannot be held responsible for any use which may be made of the information contained therein. The authors also acknowledge the invaluable help and support provided by José Luis Ferrando and TEDAX (Spanish EOD specialists), with regards to carrying out the controlled explosions and the recovery evidence process. Félix Zapata would like to acknowledge the $\mathrm{PhD}$ research scholarship from Spanish Ministry of Education. The authors also would like to thank Ignacio Jimeno for the assistance with figures and graphic arts.

\section{References}

[1] Marshall, M.; Oxley, J. Aspects of Explosives Detection, Elsevier: Netherlands, 2009.

[2] Yinon, J. Counterterrorist Detection Techniques of Explosives, Elsevier: Netherlands, 2007.

[3] Caygill, J. S.; Davis, F.; Higson, S. P. J. Talanta 2012, 88, 14-29.

[4] Tarvin, M.; McCord, B.; Mount, K.; Miller, M. L. Forensic Sci. Int. 2011, 209, 166-172.

[5] Borusiewicz, R.; Zadora, G.; Zieba-Palus, J. Talanta 2013, 116, 630-636.

[6] Krull, I. S.; Davis, E. A.; Santasania, C.; Kraus, S.; Basch, A.; Bamberger, Y. Anal. Lett. 1981, 14:16, 1363-1376.

[7] Kolla, P.; Sprunkel, A. J. Forensic Sci. 1995, 40:3, 406-11. 
[8] Calderara, S.; Gardebas, D.; Martinez, F. Forensic Sci. Int. 2003, 137, 6-12.

[9] Xu, X.; Koeberg, M.; Kuijpers, C. J.; Kok, E. Sci. Jus. 2014, 54, 3-21.

[10] Hansson, H.; Elfving, A.; Menning, D.; Önnerud, H. G.; Holmgren, E.; Brantlind, M.; Hedebrant, U.; Östmark, H.; Karlsson, R. M.; Goede, P. Proc. SPIE 2011, 8189, 818903/1$818903 / 10$.

[11] Joshi, M.; Rigsby, K.; Almirall, J. R. Forensic Sci. Int. 2011, 208, 29-36.

[12] Marsh, C. M.; Mothershead, R. F.; Miller, M. L. Sci. Jus. 2015, 55, 299-306.

[13] Téllez, H.; Vadillo, J. M.; Laserna, J. J. Rapid Commun. Mass Spectrom. 2012, 26, $1203-$ 1207.

[14] Johns, C.; Shellie, R. A.; Potter, O. G.; O’Reilly, J. W.; Hutchinson, J. P.; Guijt, R. M.; Breadmore, M. C.; Hilder, E. F.; Dicinoski, G. W.; Haddad, P. R. J. Chromatogr. A 2008, $1182,205-214$.

[15] Dicinoski, G. W.; Shellie, R. A.; Haddad, P. R. Anal. Lett. 2006, 39:4, 639-657.

[16] Pumera, M. Electrophoresis 2006, 27, 244-256.

[17] Hutchinson, J. P.; Evenhuis, C. J.; Johns, C.; Kazarian, A. A.; Breadmore, M. C.; Macka, M.; Hilder, E. F.; Guijt, R. M.; Dicinoski, G. W.; Haddad, P. R. Anal. Chem. 2007, 79, 70057013.

[18] Hutchinson, J. P.; Johns, C.; Breadmore, M. C.; Hilder, E. F.; Guijt, R. M.; Lennard, C.; Dicinoski, G.; Haddad, P. R. Electrophoresis 2008, 29, 4593-4602.

[19] Blanco, G. A.; Nai, Y. H.; Hilder, E. F.; Shellie, R. A.; Dicinoski, G. W.; Haddad, P. R.; Breadmore, M. C. Anal. Chem. 2011, 83, 9068-9075.

[20] Sarazin, C.; Delaunay, N.; Costanza, C.; Eudes, V.; Gareil, P. Electrophoresis 2011, 32, $1282-1291$.

[21] Sarazin, C.; Delaunay, N.; Varenne, A.; Vial, J.; Costanza, C.; Eudes, V.; Mineta, J. J.; Gareil, P. J. Chromatogr. A 2010, 1217, 6971-6978.

[22] Martín-Alberca, C.; Fernández de la Ossa, M. A.; Saiz, J.; Ferrando, J. L.; García-Ruiz, C. Electrophoresis 2014, 35, 3272-3280.

[23] Kuula, J.; Rinta, H.; Pölönen, I.; Puupponen, H. H.; Haukkamäki, M.; Teräväinen, T. Proc. SPIE 2014, 9073, 90730Q/1-90730Q/12.

[24] Banas, K.; Banas, A.; Moser, H. O.; Bahou, M.; Cholewa, M.; Yang, P.; Lim, S. K. Diamond Light Source Proceedings, 2011, 1, e125 doi:10.1017/S2044820110000900

[25] Banas, A.; Banas, K.; Bahou, M.; Moser, H. O.; Wen, L.; Yang, P.; Li, Z. J.; Cholewa, M.; Lim, S. K.; Lim, C. H. Vibrational Spectrosc. 2009, 51, 168-176.

[26] Martín-Alberca, C.; Zapata, F.; Carrascosa, H.; Ortega-Ojeda, F. E.; García-Ruiz, C. Talanta 2016, 149, 257-265.

[27] Almeida, M. R.; Correa, D. N.; Zacca, J. J.; Logrado, L. P. L.; Poppi, R. J. Anal. Chim. Acta 2015, 860, 15-22. 
[28] Zhang, C.; Wang, K.; Han, D.; Pang, Q. Spectrochim. Acta A 2014, 122, 387-391.

[29] Sil, S.; Chaturvedi, D.; Krishnappa, K. B.; Kumar, S.; Asthana, S. N.; Umapathy, S. Phys. Chem. A 2014, 118, 2904-2914.

[30] Calzzani, F. A.; Sileshi, R.; Kassu, A.; Taguenang, J. M.; Chowdhury, A.; Sharma, A.; Ruffin, P. B.; Brantley, C.; Edwards, E. Proc. SPIE 2008, 6945, 694510/1-694510/9.

[31] Al-Saidi, W. A.; Asher, S. A.; Norman, P. J. Phys. Chem. A 2012, 116, 7862-7872.

[32] Lin-Vien, D.; Colthup, N. B.; Fateley, W. G.; Graselli, J. G. The Handbook of Infrared and Raman Characteristic Frequencies of Organic Molecules, Academic Press: San Diego, 1991.

[33] Almaviva, S.; Botti, S.; Cantarini, L.; Palucci, A.; Puiu, A.; Rufoloni, A.; Landström, L.; Romolo, F. S. Proc. SPIE 2012, 8546, 854602/1-854602/7.

[34] Gruzdkov, Y. A.; Gupta, Y. M. J. Phys. Chem. A 2001, 105, 6197-6202.

[35] Brauera, B.; Dubnikova, F.; Zeiri, Y.; Kosloff, R.; Gerber, R. B. Spectrochim. Acta A 2008, 71, 1438-1445.

[36] Oxley, J.; Smith, J.; Brady, J.; Dubnikova, F.; Kosloff, R.; Zeiri, L.; Zeiri, Y. Appl. Spectrosc. 2008, 62, 906-915.

[37] Sülzle, D.; Klaeboe, P. Acta Chem. Scand. A 1988, 42, 165-170.

[38] Nakamoto, K. Infrared and Raman spectra of inorganic and coordination compounds, Part A. Theory and applications in inorganic chemistry, 6th edition, John Wiley and Sons Inc.: New York, 2009.

[39] López-López, M.; Ferrando, J. L.; García-Ruiz, C. Anal. Chem. 2013, 85, 2595-2600.

[40] Ali, E. M. A.; Edwards, H. G. M.; Scowen, I. J. Talanta 2009, 78, 1201-1203.

[41] Zapata, F.; Fernández de la Ossa, M. A.; Gilchrist, E.; Barron L.; García-Ruiz, C. Talanta (May 2016 accepted). 